\title{
MECHANICAL PROPERTIES IMPROVEMENT OF FIBER REINFORCED CONCRETE
}

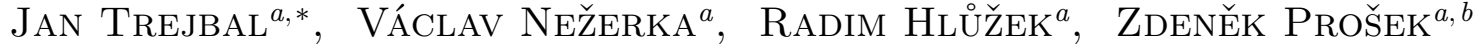 \\ ${ }^{a}$ Czech Technical University in Prague, Faculty of Civil Engineering, Thákurova 7, 166 29 Prague, Czech \\ Republic \\ ${ }^{b}$ Czech Technical University in Prague, University Centre for Energy Efficient Buildings, Třinecká 1024, 27343 \\ Buštěhrad, Czech Republic \\ * corresponding author: jan.trejbal@fsv.cvut.cz
}

ABstract. Fiber reinforced concrete mechanical properties are limited due to low adhesion between polymer fibers and cement matrix. To ensure a strong interaction between the two materials, polypropylene fibers $(d=0.305 \mathrm{~mm})$ were modified by an oxygen plasma treatment. The interface interaction was moreover activated using finely ground concrete recyclate, whose individual grains (1-64 $\mathrm{mm})$ ensure an adhesion improvement in interfacial zones. The adhesion enhancement was verified by pull-out tests, when reference and modified fibers were pulled-out from cement matrix specimens. Such obtained results were used as a crucial parameter to numerical simulations of bending tests of specimens $(550 \times 150 \times 150 \mathrm{~mm})$ with properties following fiber reinforced concrete. It was shown that samples reinforced with modified fibers and contained activating recyclate reached on higher residual bending strength then those with reference fibers.

KEYWORDS: Fiber reinforced concrete, macro fibers, polymer fibers, interfacial shear stress.

\section{INTRODUCTION}

Fiber reinforced concrete (FRC) has became popular at production of prefabricated concrete materials, shotcretes, and industrial high-loaded floors. Such material is composed from polymeric macro-fibers (amount ca. up to $1 \%$ vol. of whole mixture), cement, and aggregate [1, 2].

Technical standards EN 14845-1 and EN 14845-2 describe FRC as structural concrete reinforced with fibers having static effect and fulfilling requirements of EN 14889-2. During three-point bending test of notched specimens $550 \times 150 \times 150 \mathrm{~mm}$, such $\mathrm{FRC}$ has to exhibit, besides, residual strength at least $1.5 \mathrm{MPa}$ at crack mouth opening displacement (CMOD) of $0.5 \mathrm{~mm}$ (corresponding deflection $0.47 \mathrm{~mm}$ ). It is clear that such behavior differentiates the FRCs from strain hardening or engineered composites, where strain-hardening response is required after reaching the elastic limit [1].

D. J. Kim et al. explained that strength limit of a fibrous composite material (including FRC) is a function of fibers volume, fibers length to diameter ratio, and the interfacial interaction between fiber surfaces and matrix. In the field of FRCs, it means that increasing fibers amount weakens the cement matrix mechanical properties in the stage of elastics response during loading. It is therefore clear that fibers amount should be as small as possible. On the other side, once matrix limit of proportionality is reached and the matrix is damaged by the crack, fibers transfer the acting stress across the crack (crack bridging) and thus ensure macroscopic integrity of whole material. Amount of stress transfered via fibers depends especially on their number and on adhesion between fiber surfaces and the cement matrix [3].

However, such adhesion is mostly too poor, especially between polymeric fibers and the cement matrix due to fibers smooth and chemically inert surfaces (related to cement matrix) 4, 5. Mechanical potential of fibers - tensile strength - is therefore unused.

To avoid issues connected with the poor adhesion between the two materials, some researches have applied additional treatment of fibers in order to decrease their surface free energy and to increase their morphology, both ensuring improvement of bond to the matrix. For these purposes, several types of treatment may be employed, e.g. chemical (use of high alkali solutions) and physical (mechanical roughening) [6 8]. Plasma modification has shown to be a promising technology, combining both the chemical (etching) and physical (roughening caused by a ion bombardment) treatment, as proven by Li et al. from the early 1990s [9, 10] and many other researches later, e.g. 1114. It is also worth noting that such treatment has been extended through many industrial fields over the past few years, especially for the surface treatment (roughening, activating, cleaning) of polymeric materials [15. Therefore, there is no obstacle to apply such technology during surface treatment of the fibers.

Although a benefit of fiber surface treatment was proven from the perspective of "surface science" many times, this was not achieved from the practical point of view, including the field of FRCs. To connect theoretical findings with praxis of civil engineering, we studied an influence of plasma modified fibers on 
mechanical properties of FRC samples using numerical simulations, following EN 14845-1.

\section{INTERACTION BETWEEN FIBER AND MATRIX}

Post-cracking response of FRC is influenced by behavior of one fiber that is pulled out from the matrix. This phenomenon was described by $\mathrm{Ch}$. Li et al. and C. Redon et al. [16, 17. The behavior is divided into two stages, the first describes chemical interaction between the two materials $\left(P_{d e b}\right)$, while the second mechanical interaction activated by fiber movement out of the matrix $\left(P_{\text {pull }}\right)$, concretely:

$$
P_{d e b}=\sqrt{\frac{\pi^{2} E_{f} d_{f}^{3}}{2}\left(\tau_{0} u+G_{d}\right)}
$$

and

$$
\begin{gathered}
P_{\text {pull }}=\pi d_{f} \tau_{0}\left[1+\frac{\beta\left(u-\left(\frac{2 \tau_{0} L_{e}^{2}}{E_{f} d_{f}}+\sqrt{\frac{8 G_{d} L_{e}^{2}}{E_{f} d_{f}}}\right)\right)}{d_{f}}\right] \times \\
{\left[L_{e}-u+\left(\frac{2 \tau_{0} L_{e}^{2}}{E_{f} d_{f}}+\sqrt{\frac{8 G_{d} L_{e}^{2}}{E_{f} d_{f}}}\right)\right],}
\end{gathered}
$$

and $\tau_{0}$, as a frictional stress after sudden drop following the peak pull-out load, by:

$$
\tau_{0}=\frac{P_{\text {pull }}}{\pi d_{f} L_{e}}
$$

where $E_{f}$ is Young's modulus of elasticity of fibers; $d_{f}$, fibers diameter; $\tau_{0}$, interfacial shears tress between fiber surface and matrix; $u$, fiber free-end displacement; $G_{d}$, interfacial bond strength; $\beta$, a shear retention factor, parameter describing slip softening / hardening behavior; $L_{e}$, fiber embedded length.

\section{Fibers AND THEIR TREATMENT}

\subsection{POLYMERIC FIBERS}

Polymeric macro-fibers were used for all experiments described below. Their geometrical and mechanical properties were as follows: material, polypropylene (PP); morphology, smooth; length, $60 \mathrm{~mm}$; diameter, $305 \mathrm{\mu m}$; density, $900 \mathrm{~kg} / \mathrm{m}^{3}$; Young's modulus of elasticity, 6.1 GPa; tensile strength, $440 \mathrm{MPa}$; elongation, $8 \%$. Mechanical properties have been determined experimentally, as reported in [18].

\subsection{Fiber Treatment}

Two fiber types were used: reference (further marked as R) and plasma treated (P30 and P120 according to treatment duration). Plasma treatment was executed using Tesla VT214 device. Treatment parameters were: plasma, cold; gas, oxygen; power of RF source, $100 \mathrm{~W}$; gas pressure, $20 \mathrm{~Pa}$; treatment duration, 30 and 120 seconds.

\begin{tabular}{lccc}
\hline Name & $\begin{array}{c}\text { Cement } \\
\text { [wt. \%] }\end{array}$ & $\begin{array}{c}\text { Recyclate } \\
\text { [wt. \%] }\end{array}$ & $\begin{array}{c}\text { W/C } \\
{[-]}\end{array}$ \\
\hline Ref & 100 & 0 & 0.40 \\
Rec & 70 & 30 & 0.41 \\
\hline
\end{tabular}

TABLE 1. Weight proportions of cement matrices.

\section{Pull-out tests}

Two matrices were used to carry out pull-out tests. The reference matrix (Ref) was made from Portland cement CEM I 42.5R and the modified matrix (Rec) contained 30 wt. \% concrete recyclate as a substitution for cement at the form of finely ground powder. The recyclate was used to fill interfacial zones between fiber surfaces and surrounding matrix and thus to ensure the adhesion between the two materials with individual grains. Grain size differed between 1-64 $\mathrm{mm}$, as measured by Blain's method. Matrices compositions are summarized in Table 1. Specimens made from such matrices had dimensions equal to $25 \times 20 \times 30 \mathrm{~mm}$, contained a single fiber in their centerline (fiber embedded length was equal to samples height $-30 \mathrm{~mm}$ ). Results of this experiment were used as basic input values for numerical modeling of FRC bending tests.

The whole experiment was carried out using loading frame Veb Tiw Rauenstein FP100. The specimen was anchored by its matrix body to a static part of the frame, while the single fiber, protruded from the specimen body, was caught by a moving frame part. The experiment was displacement controlled at the constant rate of $3 \mathrm{~mm} / \mathrm{min}$, finished after reaching to $4.5 \mathrm{~mm}$ of fiber-free end displacement (only $\mathrm{R}$ and P30 were further used).

Results from pull-out tests - dependence between fiber free-end displacement and force resisting to that - are summarized in Figure 1. It is clear from these results that the maximal force recorded during pullout reference fiber $(\mathrm{R})$ from the reference matrix (Ref) slightly overcame $10 \mathrm{~N}$, while in the case of 30 seconds plasma modified fibers (P30) and matrix containing concrete recyclate $(\mathrm{Rec})$, the force reached on more than 14 N. Despite of the assumptions, fibers exposed to plasma for 120 seconds (P120) exhibited adhesion to the matrix worse than these modified for 30 seconds. This could be caused by their diameter reduction due to too long treatment. Therefore, such fibers were not used for numerical simulations described below. According to equation (4), shear stresses were calculated from thus obtained results. It was calculated that $\tau_{0, R}=3.24 \cdot 10^{5} \mathrm{~Pa}$ and $\tau_{0, P 30}=4.56 \cdot 10^{5} \mathrm{~Pa}$ in the case of reference and 30 seconds modified fibers, respectively.

\section{NumERICAL SIMULATIONS}

Numerical simulations followed procedure of threepoint bending test described in technical standard 


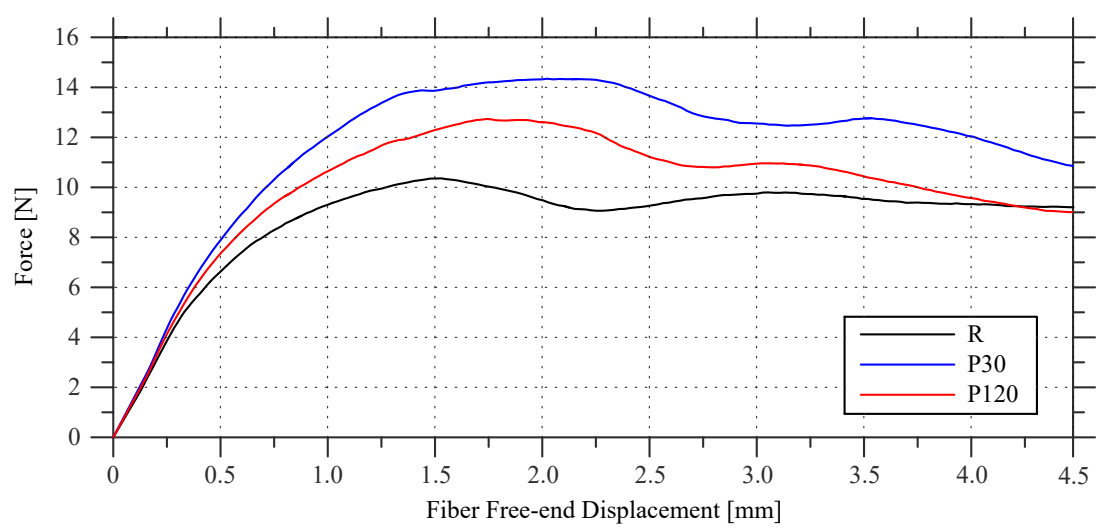

Figure 1. Pull-out behavior of reference and modified fibers.
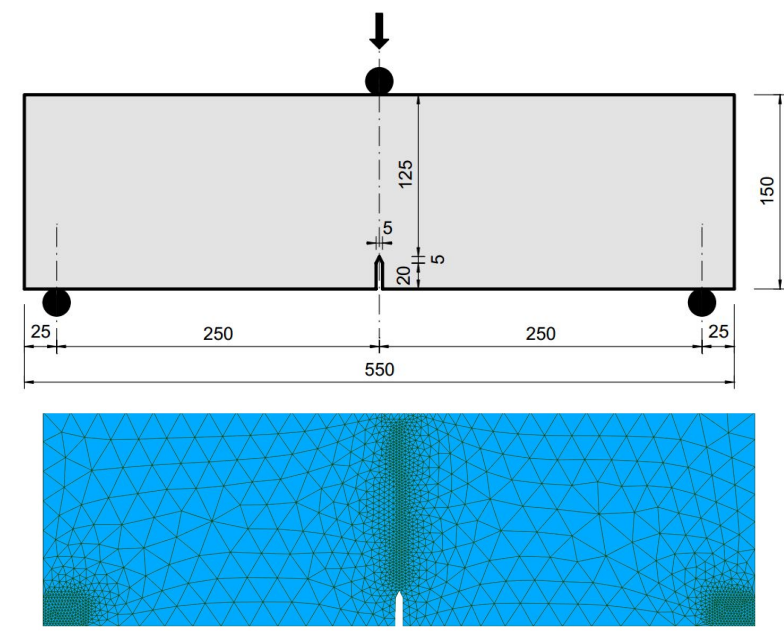

Figure 2. Geometry of FRC specimen (top) and mesh of computational model (bottom).

EN 14845-2. As already mentioned in Introduction, notched FRC specimen $550 \times 150 \times 150 \mathrm{~mm}$, containing 0.5 vol. $\%$ of fibers, has to exhibit at least $1.5 \mathrm{MPa}$ of bending strength in post-cracking phase during midspan deflection of $0.47 \mathrm{~mm}$. To avoid lengthy experimental testing, numerical simulation was employed. SHCC material model [19, 20, suitable also for FRCs, was applied. Mash of the 2D model, counting 3080 of predominantly triangle linear elements, was created in Salome software [21]. Non-linear numerical analysis was conducted using OOFEM software [22], proceeded in 800 steps. Numerical experiment was controlled by displacement. Solution was searched by Newton-Raphson's method. The stiffness matrix was compiled in 2D plain-stress preposition. Geometry of the specimen and mesh of finite elements are shown in Figure 2

Two calculations were done; the first contained reference, while the second one 30 seconds plasma modified fibers. Mechanical properties of matrix was set to correspond common concrete. All parameters set to numerical model were as follows (reference / modified fibers): $E$ Young's modulus of elasticity of matrix, 20 / $20 \mathrm{GPa} ; \nu$ Poisson's ratio of matrix, $0.2 / 0.2 ; G_{f}$ fracture energy of matrix, $5.0 / 5.0 \mathrm{~N} / \mathrm{m} ; f_{t}$ tensile strength of matrix, 2.5 / 2.5 MPa; softType a parameter describing post-peak behavior, 3 / 3: Hordijk's softening; shearType a parameter describing shear stiffness of cracked material, 1/1: constant shear retention; shearStrength Type a parameter limiting the magnitude of resulting shear stress acting on crack plane; $1 / 1$ : the threshold is set to the value of the tensile strength; $V_{f}$ fiber volume ratio, $0.005 / 0.005 ; D_{f}$ fiber diameter, $0.305 / 0.305 \mathrm{~mm} ; D_{f}$ fiber length, $60.0 / 60.0 \mathrm{~mm} ; E_{f}$ Young's modulus of elasticity of fibers, 6.1/6.1 GPa; $G_{f}$ shear modulus of fibers, $1.0 / 1.0 \mathrm{GPa} ; \tau_{0}$ frictional shear stress between the fiber and the matrix during debonding, $0.324 / 0.456 \mathrm{MPa} ; f$ snubbing coefficient; $0.5 / 0.5 ; k_{f}$ fiber cross-section shape correction factor, $0.9 / 0.9$; FSStype a class describing type of fiber bond shear strength, $0 / 0$ : constant shear strength; fiberType class of reinforcing fibers, 2 / 2: short randomly oriented fibers; $n$ Cracks maximal number of cracks, 2 / $2 ; M$ exponent related to fiber unloading, $1 / 1$; fibreActivationOpening, $10^{-6} / 10^{-6} ; d_{w 0}$ lower bond allowing to smoothen the traction-separation law for fibers, $10^{-7} / 10^{-7} ; d_{w 1}$ upper bond allowing to smoothen the traction-separation law for fibers, $10^{-7} / 10^{-7}$.

\section{Results}

It was found from numerical simulations that residual strength of FRC specimen reinforced with plasma modified fibers (P30) at amount of 0.5 vol.\% tightly exceeded 1.5 MPa at CMOD of $0.47 \mathrm{~mm}$. In the same stage, the samples containing reference fibers exhibited only ca. 1.3 MPa. Results from both simulations are imagined in Figure 3 , where the green line highlights the minimal bending strength required by EN 148452. It is obvious from these results that only FRC containing modified fibers fulfilled these requirements, so this can be considered as structural.

These simulations also revealed that the behavior of both specimens was practically identical in phases 


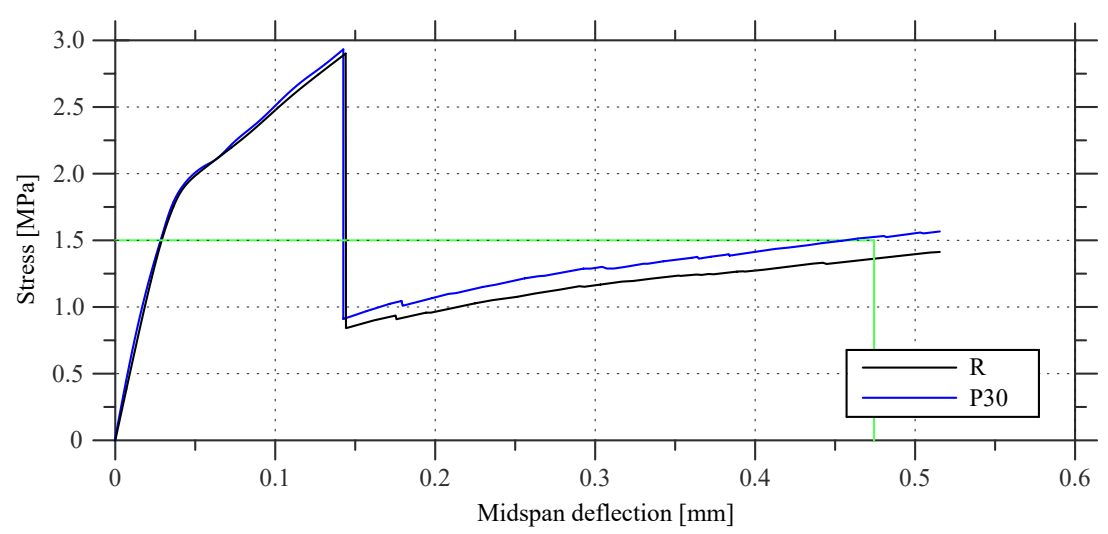

FiguRE 3. Normal tension as a function of midspan displacement.

until the fibers have not been activated yet. After, fibers bridged the opening crack, transfered acting stress and thus ensured macroscopic integrity of specimens. Based on the specimens post-cracking behavior, it is clear that the adhesion between modified fibers and the matrix was increased than in case of reference fibers. This finding proves that interfacial shear stress between the two materials plays an important role from the mechanical response point of view.

\section{Conclusions}

This work deals with searching of mechanical behavior of fiber reinforced concrete using numerical simulations of three-point bending tests. Reference and plasma modified polypropylene fibers $(\mathrm{d}=0.305)$ were used as reinforcement. Adhesion between these fibers and two types of the cement matrix was examined employing pull-out test. The purpose of the simulation was to find residual bending strength of specimens, following relevant technical standards. Finding were as follows:

- Adhesion between 30 seconds oxygen plasma treated fibers and the cement matrix containing concrete recyclate was higher by approx. $15 \%$ then in the case of reference fibers and reference cement matrix.

- 120 seconds lasting plasma treatment did not bring any benefits in terms of adhesion improvement. Conversely, such treated fibers showed worse adhesion to the matrix than those 30 seconds exposed to plasma. This was probably caused by their diameter reduction as a consequence of too intensive ion bombardment.

- Numerical simulations revealed that residual strength of reference FRC at the midspsan deflection of $0.47 \mathrm{~mm}$ was less than $1.5 \mathrm{MPa}$, so this material did not meet requirements of technical standard EN 14845-2. On the other side, if plasma treated fibers and the cement matrix containing $30 \mathrm{wt} . \%$ of concrete recyclate were used, residual strength overcame minimal 1.5 $\mathrm{MPa}$.

\section{ACKNOWLEDGEMENTS}

This work was financially supported by Czech Technical University in Prague - SGS project SGS16/201/OHK1/3T/11 and SGS18/037/OHK1/1T/11, and by the Czech Science Foundation research project 17-06771S. Special thanks to Tereza Horová for research assistance.

\section{REFERENCES}

[1] M. Prisco, G. Plizzari, L. Vandewalle. Fibre reinforced concrete: new design perspectives. Materials and Structures 42(9):1261-1281, 2009.

[2] P. Tatnall. Fiber-reinforced concrete. In Significance of Tests and Properties of Concrete and ConcreteMaking Materials, chap. 49. ASTM International, 2006.

[3] D. Kim, E. Naaman, S. El-Tawil. High performance fiber reinforced cement composites with innovative slip hardending twisted steel fibers. International Journal of Concrete Structures and Materials 3(2):119-126, 2009. DOI:10.4334/IJCSM.2009.3.2.119.

[4] M. Halvaei, M. Jamshidi, M. Latifi. Investigation on pullout behavior of different polymeric fibers from fine aggregates concrete. Journal of Industrial Textiles 45(5):995-1008, 2006. DOI:10.1177/1528083714551437

[5] W. Choi, S. Jang, H. Yun. Interface bond characterization between fiber and cementitious matrix. International Journal of Polymer Science pp. 995-1008, 2015. DOI:10.1155/2015/616949.

[6] V. Machovič, V. Lapčák, L. Borecká, et al. Microstructure of interfacial transition zone between pet fibres and cement paste. Acta Geodyn Geomater 10(1):121-127, 2013. DOI:10.13168/AGG.2013.0012.

[7] A. Tagnit-Hamou, Y. Vanhove, N. Petrov. Microstructural analysis of the bond mechanism between polyolefin fibers and cement pastes. Cement and Concrete Research 35(2):364-370, 2005. DOI:10.1016/j.cemconres.2004.05.046

[8] L. Yan, R. Pendleton, C. Jenkins. Interface morphologies in polyolefin fiber reinforced concrete composites. Composites Part A: Applied Science and Manufacturing 29(5-6):643-650, 1998. DOI:10.1016/S1359-835X(97)00114-0 
[9] V. Li, Y. Chan, H. Wu. Interface strengthening mechanisms in polymeric fiber reinforced cementitious composites. In Proceedings of conference on Brittle Matrix Composites 4. IKE and Woodhead, Warsaw, 1994.

[10] V. Li, H. Stang. Interface property characterization and strengthening mechanisms in fiber reinforced cement based composites. Advanced Cement Based Materials 6(1):1-20, 1997. DOI:10.1016/S1065-7355(97)90001-8

[11] B. Felekoglu, K. Tosun, B. Baradan. A comparative study on the flexural performance of plasma treated polypropylene fiber reinforced cementitious composites. Journal of Materials Processing Technology 209:51335144, 2009. DOI:10.1016/j.jmatprotec.2009.02.015

[12] J. Trejbal, V. Nežerka, M. Somr, et al. Deterioration of bonding capacity of plasma-treated polymerfiber reinforcement. Cement and Concrete Composites 89:205215, 2018. DOI:10.1016/j.cemconcomp.2018.03.010

[13] A. Pamreddya, D. Skácelová, M. Haniǎinec, et al. Plasma cleaning and activation of silicon surface in dielectric coplanar surface barrier discharge. Surface and Coatings Technology 236:326-331, 2013. DOI:10.1016/j.surfcoat.2013.10.008

[14] T. Homola, J. Matoušek, B. Hergelová, et al. Activation of poly(ethylene terephthalate) surfaces by atmospheric pressure plasma. Polymer Degradation and Stability 97(11):2249-2254, 2012. DOI:10.1016/j.polymdegradstab.2012.08.001.

[15] J. Reece Roth. Industrial Plasma Engineering. Volume 2: Applications to Nonthermal Plasma Processing. CRC Press, Boca Raton, 2001.
[16] V. Li, C. Leung. Steady-state and multiple cracking of short random fiber composites. Journal of Engineering Mechanics 118(11):2246-2264, 1992. DOI:10.1061/(ASCE)0733-9399(1992)118:11(2246).

[17] C. Redon, V. Li, C. Wu, et al. Measuring and modifying interface properties of pva fibers in ecc matrix. Journal of Materials in Civil Engineering 13(6):399-406, 2001. DOI:10.1061/(ASCE)0899-1561(2001)13:6(399)

[18] R. Hlůžek. Analysis and modification of interfacial zones between cementitious matrix and fiber reinforcement. Diploma thesis. CTU in Prague, Faculty of Civil Engineering, Czech Republic, 2018.

[19] K. Toshiyuki, P. Kabele, H. Fukuyama, et al. Strain hardening cement composites: Structural design and performance. In State-of-theArt Report of the RILEM Technical Committee 208-HFC, SC3. Springer, Dordrecht, 2012.

[20] P. Havlásek, P. Kabele. A detailed description of the computer implementation of SHCC material model in OOFEM, CTU in Prague.

[21] SALOME Platform, on-line, available from: http://www.salomeplatform.org/usersection/about/mesh.

[22] B. Patzák. OOFEM - an object-oriented simulation tool for advanced modeling of materials and structures. Acta Polytechnica 6(6):59-66, 2012. 